\title{
Impact of COVID-19 on Academic and Psychological aspects of Undergraduate Students in Bangladesh: A Case Study
}

\author{
Md. Mortuza Ahmmed, M. Mostafizur Rahman, Abhijit Bhowmik, Ayesha Siddiqua
}

\begin{abstract}
Undergraduate students are considered susceptible in terms of anxiety, drug abuse, depression, and bad dietary habits in comparison to the general people. Their academic and psychological facets have severely been altered due to COVID-19 pandemic. The objective of this study is to identify the effect of COVID-19 on the academic and psychological aspects of undergraduate students in Bangladesh accompanied by other pertinent factors. Data were accumulated from the undergraduate students of the Fall semester 2020-21 of American International University-Bangladesh (AIUB) by questionnaire provided through Microsoft Forms. The associations among the variables were assessed through the chi-square test. All the statistical analyses required to meet the goals of the study were done through Statistical Package for Social Sciences (SPSS). Nearly one-fourth of the students suffered from anxiety and depression at an extreme level while close to one-third of them suffered quite a bit signaling a tormenting psychological state of the students. Chi-square tests found that depression, anxiety, study hour, assessment of online learning, and income issue due to COVID-19 of the student had a highly significant association with effects on their study and psychological aspects. Failure to address the aforesaid issues during an epidemic might have negative consequences on the academic and psychological aspects in the long run.
\end{abstract}

Index Terms-Anxiety, Chi-square test, COVID-19, CGPA, depression, MICS.

\author{
Md. Mortuza Ahmmed \\ Assistant Professor, \\ Department of Mathematics, \\ American International university Bangladesh \\ Email: mortuza@aiub.edu \\ M. Mostafizur Rahman \\ Associate Professor, \\ Department of Mathematics, \\ American International university Bangladesh \\ Email: mostafiz.math@aiub.edu \\ Abhijit Bhowmik \\ Associate Professor, \\ Department of Computer Science, \\ American International university Bangladesh \\ Email: abhijit@aiub.edu \\ Ayesha Siddiqua \\ Assistant Professor, \\ Department of Mathematics, \\ American International university Bangladesh \\ Email: ayesha.siddiqua@aiub.edu
}

\section{INTRODUCTION}

$\mathrm{C}$ OVID-19 epidemic has affected virtually every segment of our life including education sector as well. All types of educational institutions have been experiencing impromptu stoppages all over the world since the arrival of COVID-19 and its lingering existence accompanied by responsive measures like quarantine, social distancing, isolation, lockdown etc. are worsening the situation. It has been revealed through a cross-sectional study based on 505 college and university students that economic insecurity, infection concern, insufficient supply of food, no re-creational activity as well as physical exercise had statistically significant association with the psychological aspects of the students [1]. A separate study has shown that people being circumscribed in seclusion may suffer from different types of psychological predicaments [2]. Anxiety and depression concerning COVID-19 have been detected to cause devastating strain for all $[3,4]$. Fear regarding the negative consequences of COVID-19 on economy and everyday life together with concern about academic interruptions have been found to be significantly associated with anxiety level of the students [5]. Students in developing countries have found it quite challenging in swapping to online education system, accustoming with the online evaluation procedures, collaborating with their teachers, accessibility of electronic devices and internet and accompanying cost [6]. A crosssectional study based on 217 private medical college students in Bangladesh has found that over $70 \%$ of the respondents have negative feeling concerning the effectiveness of the ongoing online education [7]. Identical results have also been found in a separate study based on 50 students from both public and private universities in Bangladesh [8].

The adjournment in educational institutions would have negative consequence both on the psychological and academic status of the students [9]. A separate study has revealed that students with lower income have higher probability of delaying their graduation than those with higher income because of the economic consequences caused by the COVID19 [10]. Financial inequality has been noticed to have significant impact on students' access to online education [11]. Education of students coming from downgraded economic status have suffered the most since the arrival of COVID-19 in Bangladesh [12]. According to Multiple Indicator Cluster 
Survey (MICS) 2019, close to 5\% families in Bangladesh do not have a mobile phone whereas nearly half of them do not have a television. Besides, merely $5.6 \%$ families possess a computer while about $37 \%$ have internet access at home which is further restricted for females in most of the households due to the male dominated family compositions in the country [13]. A different study based on students from selected public universities have also revealed that majority of the students have suffered in terms of education, income and psychology as a consequence of COVID-19 in Bangladesh [14]. Also, the online education system has been found to be more difficult to catch than the traditional one for most of the students as well [15].

Students who regularly search for information concerning COVID-19 issues have been identified not only to experience higher depression and anxiety levels but also to lose concentration on their academic activities [16]. Analytical results of a study based on 195 public university students in the USA have revealed that personal health concern, academic interruptions, sleeping instabilities, social distancing, and fear about academic results are the crucial factors of anxiety and depression of the students during COVID-19 [17]. Almost similar findings have been observed in a qualitative study based on nursing students as well [18].

It is important to investigate the academic and psychological experience of the university students in Bangladesh during the COVID-19 epidemic given the unanticipated surroundings. This study has been intended to identify these academic and psychological crises. The objective of this study is to address the impact of COVID-19 on the academic and psychological aspects among the students at tertiary level in Bangladesh along with other relevant determinants.

\section{Methodology}

Primary data for the study were assembled from the undergraduate students of the Fall semester 2020-21 of American International University-Bangladesh (AIUB). A self- directed questionnaire was developed at the beginning which was finalized only after being pretested on a sample of 50 students encircling various faculties. Almost 10000 students are there in AIUB under different faculties. Initially, a sample of size 1650 was estimated considering $2.2 \%$ margin of error at $95 \%$ confidence interval [19]. Anticipating 5\% nonresponse rate, the final sample size was adjusted as:

Final sample size

$=($ Initial sample size $) /(1$-Anticipated non-response rate $)=$ $1650 /(1-0.05) \approx 1737$

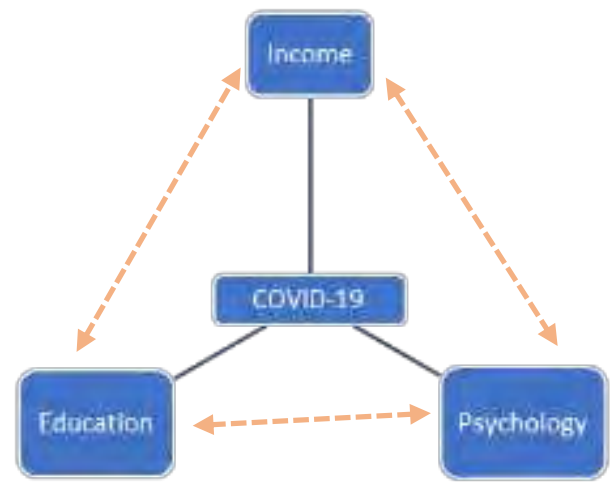

Figure 1: Conceptual framework

A total of 44 classes were selected by simple random sampling technique covering all the faculties, namely, Faculty of Arts and Social Sciences (FASS), Faculty of Business Administration (FBA), Faculty of Engineering (FE), and Faculty of Science \& Technology (FST). Each of the classes had 40 students on average resulting in a total of 1760 students. They were asked to give response to the relevant questionnaire provided through Microsoft Forms. Exactly 1715 students turned in with complete response indicating a non-response rate of nearly $2.6 \%$.

Several variables related to the study objective were considered like gender, area of residence, age, depression, anxiety, effects on study and income due to COVID-19, study hour, online learning hour, rating of online learning, COVID19 experience of the student as well as any of his/her family member, and any death case in the family from COVID- 19 . The association among the variables were assessed by applying chi-square test, where $\mathrm{p}$-value $\leq 0.05$ indicated significant association and $\mathrm{p}$-value $\leq 0.01$ indicated highly significant association. All the statistical analyses required to meet the goals of the study were accomplished through Statistical Package for Social Sciences (SPSS) - version 20.0.

\section{RESUlTS AND DISCUSSION}

The background characteristics of the respondents are illustrated in Table 1 below:

TABLE I

DISTRIBUTION OF RESPONDENTS BY BACKGROUND CHARACTERISTICS

\begin{tabular}{cccc}
\hline & & Frequency & Percentage \\
\hline \multirow{2}{*}{ Gender } & Female & 382 & 22.3 \\
& Male & 1333 & 77.7 \\
\multirow{2}{*}{ Age } & $18-20$ & 284 & 16.6 \\
& $20-22$ & 899 & 52.4 \\
& $22-24$ & 461 & 26.9 \\
Area of residence & $>24$ & 71 & 4.1 \\
& Urban & 1257 & 73.3 \\
& Rural & 458 & 26.7 \\
Study affected & Considerably & 471 & 27.5 \\
& Greatly & 496 & 28.9 \\
& Moderately & 459 & 26.8 \\
& Not affected at all & 102 & 5.9 \\
& Slightly & 187 & 10.9 \\
& $<2$ & 436 & 25.4 \\
& $2-4$ & 672 & 39.2 \\
& $4-6$ & 426 & 24.8 \\
& $6-8$ & 115 & 6.7
\end{tabular}




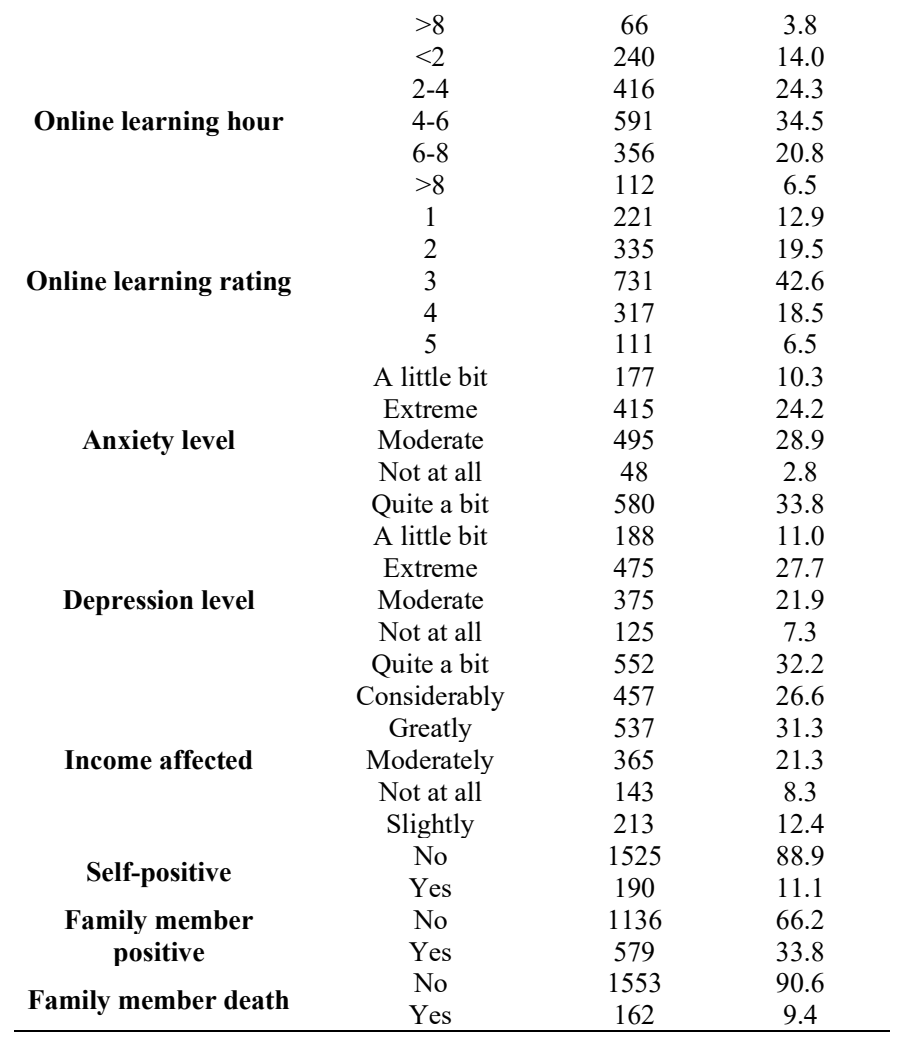

The gender ratio of the students was $3.48: 1$ signifying the preeminence of male students at AIUB. More than half of the students $(52.4 \%)$ were aged between 20 to 22 years. Figure 1 highlights the distributions of students by age and gender more evidently.

As expected, the majority of them $(73.3 \%)$ came from urban areas since tertiary education is an expensive deal in private universities in Bangladesh and is beyond reach of most of the limited stipendiary rural citizens. Distributions of how COVID-19 affected the students are displayed in figure 2 .

A significant proportion of them $(83.2 \%)$ responded that their academic study was affected to an extent due to COVID19. Around one fourth of the students were observed to study in both less than 2 hours and 4 to 6 hours category while close to $40 \%$ were found to study between 2 to 4 hours on average per day. Around one third of them used to spend 2 to 4 hours in online learning on average per day while nearly $43 \%$ of them rated the online learning as average. Distributions of students by study hour and online learning can be observed through fig 3 .

Close to one fourth of the students admitted suffering from anxiety at extreme level while little over one third of them suffered quite a bit. Almost matching outcomes were obtained for depression level as well signaling a tormenting psychological state of the students. Distributions of students by anxiety and depression are exhibited in figure 4 .

Family income of more than $90 \%$ of the students was affected due to COVID-19 to some extent. Around 11\% of the students found themselves to be COVID-19 positive. For one third of the students, any of their family members were reported as COVID-19 positive of which just over $9 \%$ cases resulted in death.

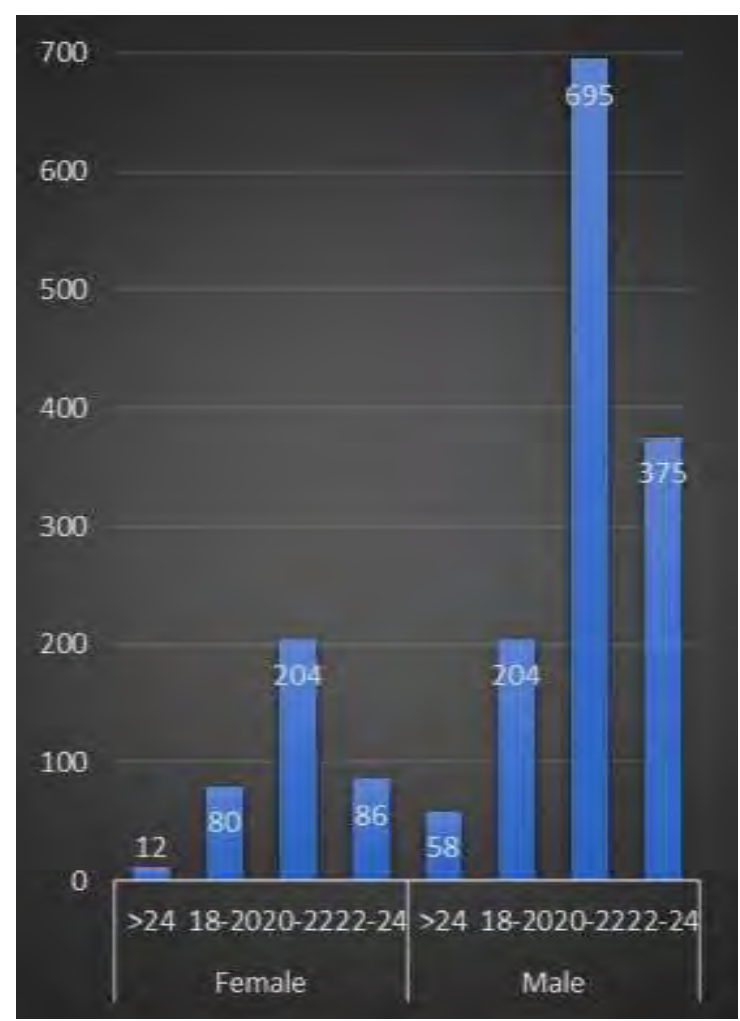

Fig. 1. Distributions of students by age and gender

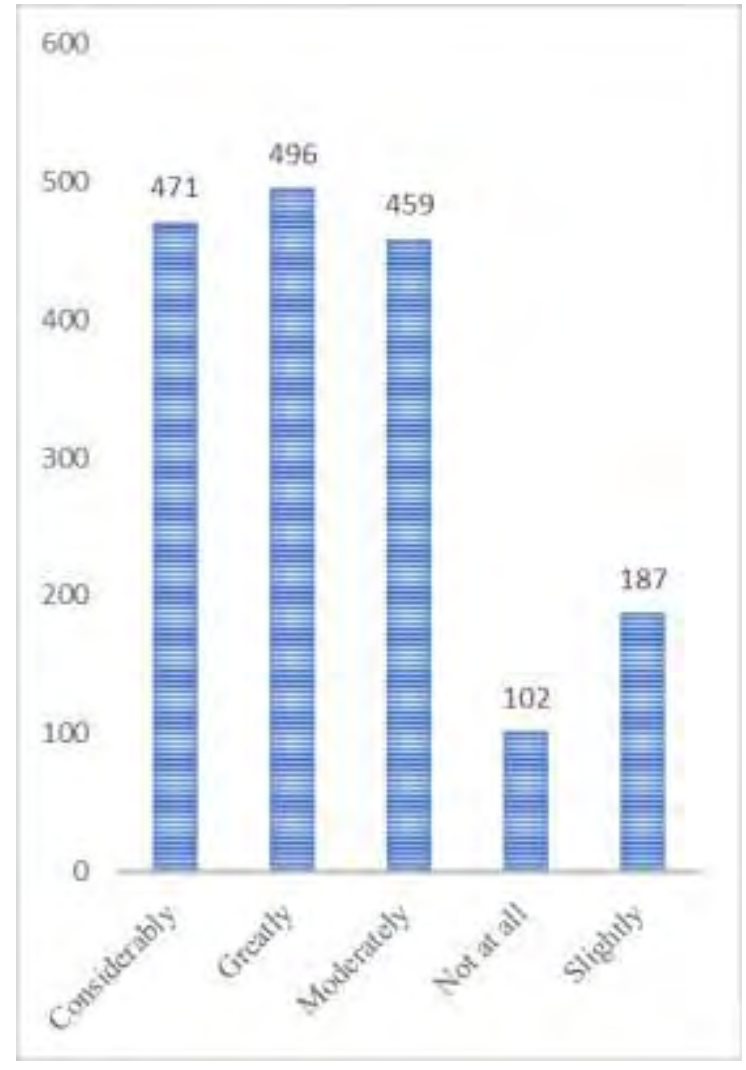

Fig. 2. Distributions of how COVID-19 affected the students 


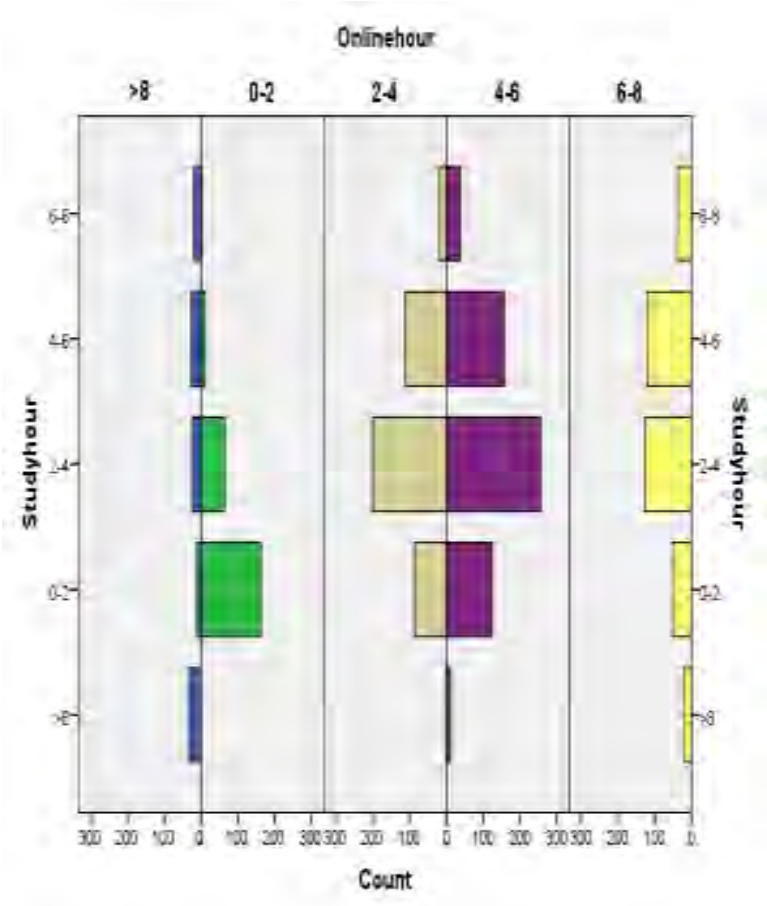

Fig. 3. Distributions of students by study hour and online learning

The association between the effects on study due to COVID-19 and the selected variables can be observed in Table 2. The analytical results of chi-square tests show that variables like depression, anxiety, study hour, rating of online learning, effects on income due to COVID-19and COVID-19 experience of the student had highly significant association with effects on study ( $p$-value $\leq 0.01$ ) while COVID-19 experience of any of his/her family member and any death case in the family from COVID-19 had significant association (p-value $\leq 0.05$ ).

The association between the depression level of the students and the selected variables can be observed in Table 3 . The analytical results of chi-square tests show that variables like gender, effects on study and income due to COVID-19, anxiety, rating of online learning, and COVID-19 experience of the student as well as any of his/her family member had highly significant association with depression level of the students (p-value $\leq 0.01$ ) while online learning and area of residence had significant association ( $p$-value $\leq 0.05$ ).

The association between the effects on study due to COVID-19 and the selected variables can be observed in Table 4 . The findings are almost similar to what are observed in Table 3.

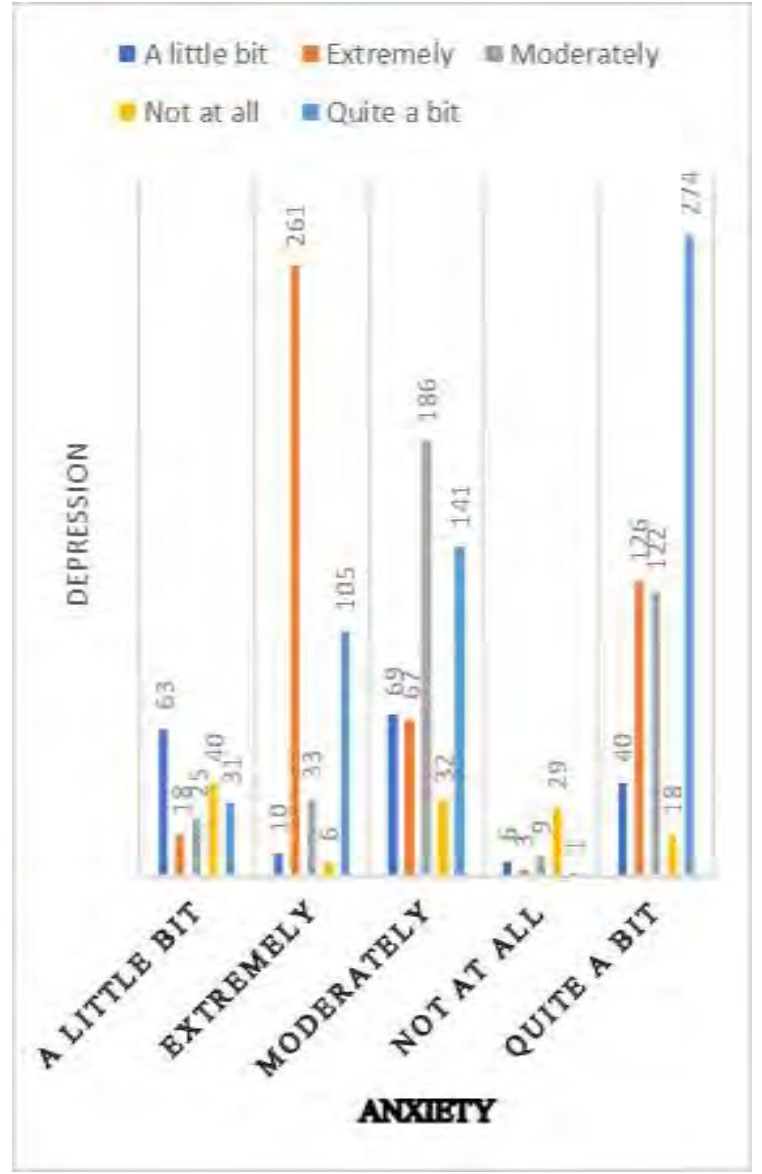

Fig. 4. Distributions of students by anxiety and depression

TABLE II

DISTRIBUTION OF RESPONDENTS BY ACADEMIC AFFECT FROM COVID-19 AND COVARIATES

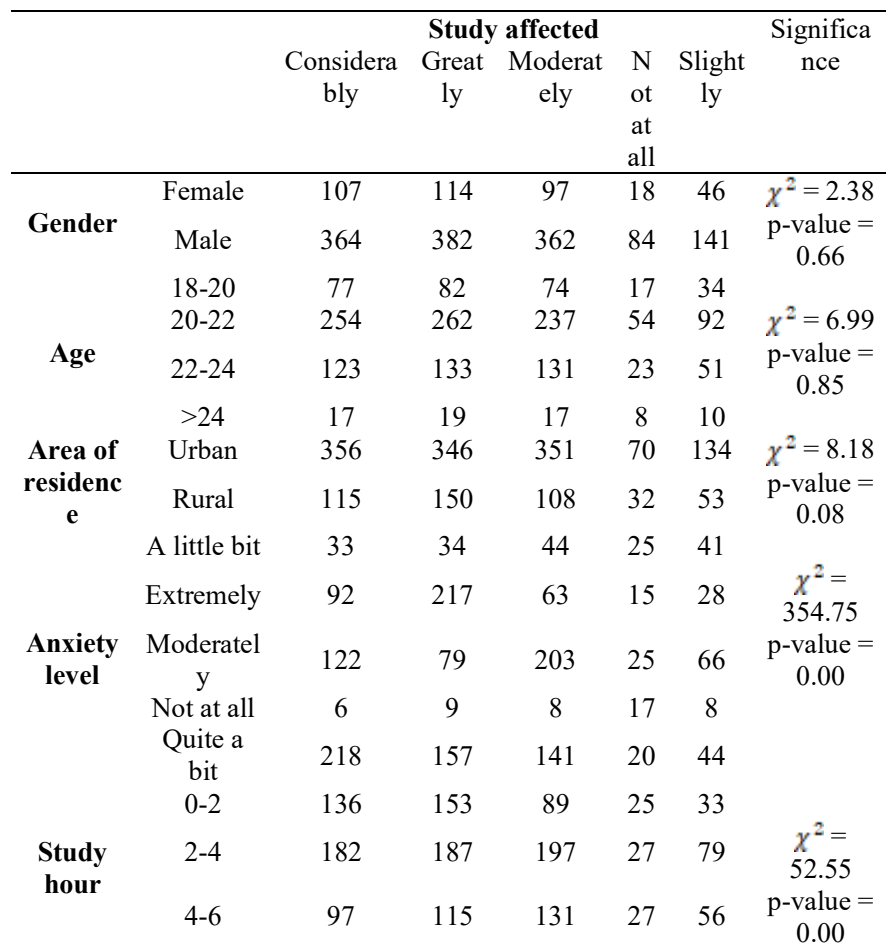




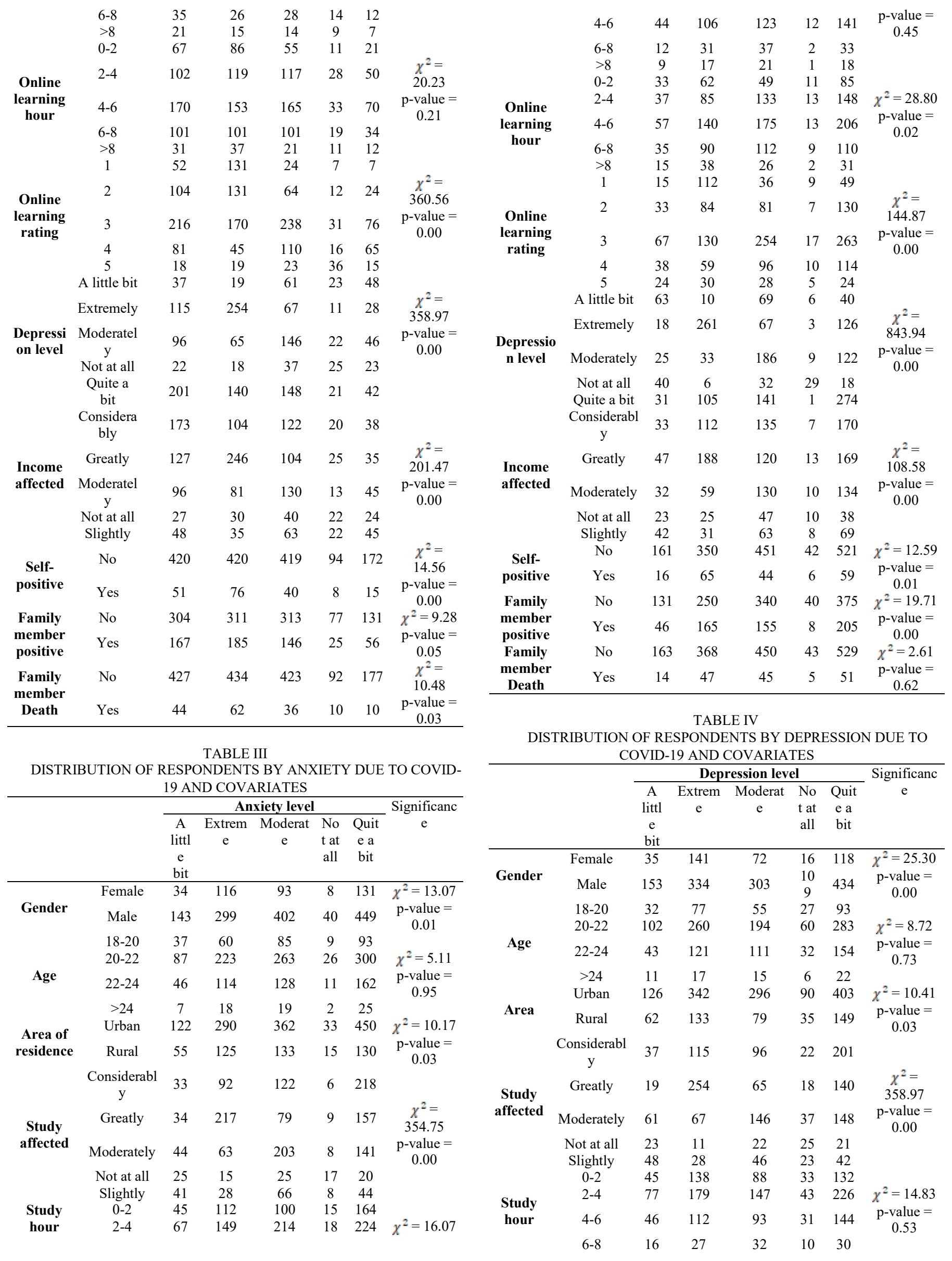




\begin{tabular}{|c|c|c|c|c|c|c|c|}
\hline \multirow{6}{*}{$\begin{array}{c}\text { Online } \\
\text { learnin } \\
\mathrm{g} \text { hour }\end{array}$} & $>8$ & 4 & 19 & 15 & 8 & 20 & \multirow{7}{*}{$\begin{array}{c}\chi^{2}=30.04 \\
\text { p-value }= \\
0.02\end{array}$} \\
\hline & $0-2$ & 30 & 64 & 58 & 18 & 70 & \\
\hline & $2-4$ & 53 & 108 & 88 & 34 & 133 & \\
\hline & $4-6$ & 64 & 152 & 135 & 29 & 211 & \\
\hline & $6-8$ & 36 & 105 & 73 & 36 & 106 & \\
\hline & $>8$ & 5 & 46 & 21 & 8 & 32 & \\
\hline \multirow{5}{*}{$\begin{array}{l}\text { Online } \\
\text { learnin } \\
\text { g rating }\end{array}$} & 1 & 10 & 118 & 29 & 13 & 51 & \\
\hline & 2 & 29 & 116 & 59 & 17 & 114 & \multirow{5}{*}{$\begin{array}{c}\chi^{2}= \\
170.87 \\
\text { p-value }= \\
0.00\end{array}$} \\
\hline & 3 & 74 & 167 & 172 & 44 & 274 & \\
\hline & 4 & 51 & 53 & 89 & 32 & 92 & \\
\hline & 5 & 24 & 21 & 26 & 19 & 21 & \\
\hline \multirow{5}{*}{$\begin{array}{l}\text { Anxiety } \\
\text { level }\end{array}$} & A little bit & 63 & 18 & 25 & 40 & 31 & \\
\hline & Extremely & 10 & 261 & 33 & 6 & 105 & \multirow{5}{*}{$\begin{array}{c}\chi^{2}= \\
843.94 \\
\text { p-value }= \\
0.00\end{array}$} \\
\hline & Moderately & 69 & 67 & 186 & 32 & 141 & \\
\hline & Not at all & 6 & 3 & 9 & 29 & 1 & \\
\hline & Quite a bit & 40 & 126 & 122 & 18 & 274 & \\
\hline \multirow{5}{*}{$\begin{array}{l}\text { Income } \\
\text { affected }\end{array}$} & $\begin{array}{c}\text { Considerabl } \\
y\end{array}$ & 39 & 121 & 108 & 15 & 174 & \\
\hline & Greatly & 39 & 225 & 77 & 24 & 172 & \multirow{4}{*}{$\begin{array}{c}\chi^{2}= \\
214.96 \\
\text { p-value }= \\
0.00\end{array}$} \\
\hline & Moderately & 36 & 72 & 117 & 25 & 115 & \\
\hline & Not at all & 34 & 22 & 31 & 22 & 34 & \\
\hline & Slightly & 40 & 35 & 42 & 39 & 57 & \\
\hline \multirow{2}{*}{$\begin{array}{c}\text { Self- } \\
\text { positive }\end{array}$} & No & 172 & 402 & 336 & $\begin{array}{c}11 \\
5\end{array}$ & 500 & $\chi^{2}=13.05$ \\
\hline & Yes & 16 & 73 & 39 & 10 & 52 & $\begin{array}{c}\mathrm{p} \text {-value }= \\
0.01\end{array}$ \\
\hline \multirow{2}{*}{$\begin{array}{c}\text { Family } \\
\text { membe } \\
\mathbf{r} \\
\text { positive }\end{array}$} & No & 134 & 269 & 263 & 97 & 373 & $\chi^{2}=31.93$ \\
\hline & Yes & 54 & 206 & 112 & 28 & 179 & $\begin{array}{c}\mathrm{p} \text {-value }= \\
0.00\end{array}$ \\
\hline \multirow{2}{*}{$\begin{array}{l}\text { Family } \\
\text { membe } \\
\text { r Death }\end{array}$} & No & 172 & 405 & 348 & $\begin{array}{c}11 \\
9\end{array}$ & 509 & $\chi^{2}=2.61$ \\
\hline & Yes & 16 & 70 & 27 & 6 & 43 & $\begin{array}{c}\mathrm{p} \text {-value }= \\
0.62\end{array}$ \\
\hline
\end{tabular}

\section{ACKNOWLEDGEMENT}

This research has been supported by RDU182201-3, UMP grant.

\section{CONCLUSION}

Undergraduate students have been going through severe psychological hardship during this ongoing COVID-19 pandemic. The future of the pandemic is uncertain and may have negative consequences on the academic and psychological aspects of undergraduate students in the long run. That is why it is important to address the impact of COVID-19 on the academic and psychological aspects of the students for the people concerned to schedule a long-term plan to control and reduce the issues.

\section{REFERENCES}

[1] Khan, A. H., Sultana, M. S., Hossain, S., Hasan, M. T., Ahmed, H. U., \& Sikder, M. T. (2020). The impact of COVID-19 pandemic on mental health \& wellbeing among home-quarantined Bangladeshi students: A cross-sectional pilot study.
[2] Brooks, S. K., Webster, R. K., Smith, L. E., Woodland, L., Wessely, S., Greenberg, N., \& Rubin, G. J. (2020). The psychological impact of quarantine and how to reduce it: rapid review of the evidence. The Lancet.

[3] Cao, W., Fang, Z., Hou, G., Han, M., Xu, X., Dong, J., \& Zheng, J. (2020). The psychological impact of the COVID-19 epidemic on college students in China. Psychiatry research, 112934.

[4] Xiao, H., Zhang, Y., Kong, D., Li, S., \& Yang, N. (2020). Social capital and sleep quality in individuals who selfisolated for 14 days during the coronavirus disease 2019 (COVID-19) outbreak in January 2020 in China. Medical science monitor: international medical journal of experimental and clinical research, 26, e923921-1.

[5] Dhar, B. K., Ayittey, F. K., \& Sarkar, S. M. (2020). Impact of COVID-19 on Psychology among the University Students. Global Challenges, 4(11), 2000038.

[6] Owusu-Fordjour, C., Koomson, C. K., \& Hanson, D. (2020). The impact of Covid-19 on learning-the perspective of the Ghanaian student. European Journal of Education Studies.

[7] Khanom, M., Hoque, A., Sharif, P. I., Sabuj, M. U., \& Hossain, M. A. (2020). How were the Online Classes in Undergraduate Medical Teaching during COVID Pandemic? Students' Views of a Non-Government Medical College in Bangladesh. Bangladesh Journal of Medical Education, 11(2), 3-13.

[8] Dutta, S., \& Smita, M. K. (2020). The impact of COVID-19 pandemic on tertiary education in Bangladesh: students' perspectives. Open Journal of Social Sciences, 8(09), 53.

[9] Chandasiri, O. (2020). The COVID-19: impact on education. Journal of Asian and African Social Science and Humanities, 6, 37-42.

[10] Aucejo, E. M., French, J., Araya, M. P. U., \& Zafar, B. (2020). The impact of COVID-19 on student experiences and expectations: Evidence from a survey. Journal of public economics, 191, 104271.

[11] Emon, E. K. H., Alif, A. R., \& Islam, M. S. (2020). Impact of COVID-19 on the Institutional Education System and its Associated Students in Bangladesh. Asian Journal of Education and Social Studies, 34-46.

[12] Shammi, M., Bodrud-Doza, M., Islam, A. R. M. T., \& Rahman, M. M. (2020). Strategic assessment of COVID-19 pandemic in Bangladesh: comparative lockdown scenario analysis, public perception, and management for sustainability. Environment, Development and Sustainability, $1-44$.

[13] Cushioning the educational fallout of Covid-19 in Bangladesh | The Daily Star. https://www.thedailystar.net/opinion/news/cushioning-theeducational-fallout-covid-19-bangladesh-1965789 (Accessed on 30 December 2020).

[14] Begum, F., Alam, S. Z. H. M. S., Alam, U. N. I. H., \& Omar, L. N. (2020). Combating the impact of COVID-19 on Public University Students through Subsidized Online Class: Evidence from Bangladesh. indicators, 11(27).

[15] Mohamed A. A. Mahdy,(2020), The Impact of COVID-19 Pandemic

on the Academic Performance of Veterinary Medical Students, Frontiers in Veterinary Science, ,Volume 7, Article 594261.

[16] Kecojevic, A., Basch, C. H., Sullivan, M., \& Davi, N. K. (2020). The impact of the COVID-19 epidemic on mental health of undergraduate students in New Jersey, crosssectional study. PloS one, 15(9), e0239696.

[17] Son, C., Hegde, S., Smith, A., Wang, X., \& Sasangohar, F. (2020). Effects of COVID-19 on college students' mental health in the United States: Interview survey study. Journal of medical internet research, 22(9), e21279.

[18] Lovrić, R., Farčić, N., Mikšić, Š., \& Včev, A. (2020). Studying During the COVID-19 Pandemic: A Qualitative Inductive Content Analysis of Nursing Students' Perceptions and Experiences. Education Sciences, 10(7), 188.

[19] Official website of Check Market, Belgium, available at https://www.checkmarket.com/ sample-size-calculator/, (accessed on 22 December 2020). 


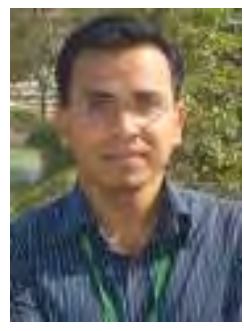

Md. Mortuza Ahmmed did his B.Sc. and M.Sc. in Statistics, Biostatistics and Informatics from University of Dhaka in 2007 and 2009 respectively. He is currently working as an Assistant Professor in Statistics under Department of Mathematics, American International University - Bangladesh.

His research interests include demography, education, epidemiology etc. He has published several articles in local and international peer reviewed journals and conferences.

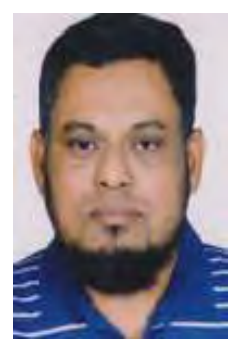

Dr. M. Mostafizur Rahman is basically a mathematician with extensive experience of mathematical modeling in multi-disciplinary environment. Dr. M. Mostafizur Rahman was born and brought up in Dhaka, Bangladesh. He completed his bachelor in mathematics and masters in applied mathematics from the University of Dhaka. He holds a $\mathrm{PhD}$ in information engineering from the University of Padova, Italy and worked as a post-doctoral research fellow for two years in the same University. He is serving as an Associate Professor in the department of Mathematics at American International UniversityBangladesh.

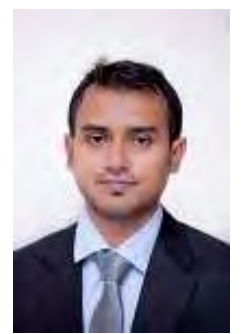

Abhijit Bhowmik Completed his B.Sc. in Computer Science \& Engineering in 2009 and M.Sc. in Computer Science in 2011 from the American International UniversityBangladesh (AIUB). Currently he is pursuing his PHD degree from University Malaysia Pahang in NLP and Machine Learning. $\mathrm{He}$ is working as Associate Professor and Special Assistant, Office of Student Affairs (OSA) in the Department of Computer Science, AIUB. His research interests include NLP, Machine Learning, wireless sensor networks, video on demand, software engineering, mobile \& multimedia communication, and data mining.

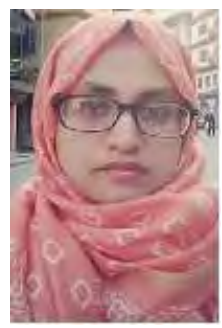

Ayesha Siddiqua is serving as an Assistant Professor in the department of Mathematics at American International UniversityBangladesh since September 2010. She has completed her MPhil degree from BUET in 2018. Her research area is Fluid Dynamics. She completed her MS in applied Mathematics in 2007(Exam held in 2009) and BSc in Mathematics in 2006(Exam held in 2008) from University of Dhaka. At present she is a PhD student of Dept. of Mathematics, BUET. Her recent research interest is Biotechnology and Fluid Dynamics 